\title{
Chromosome 7 Rearrangement
}

National Cancer Institute

\section{Source}

National Cancer Institute. Chromosome 7 Rearrangement. NCI Thesaurus. Code C150479.

A rearrangement of genomic material involving chromosome 7. 